\title{
Microstructural characterization of catalysis product of nanocement based materials: A review
}

\author{
Norsuzailina Mohamed Sutan ${ }^{1, *}$, Nur Izaitul Akma Ideris ${ }^{1}$, Siti Noor Linda Taib $^{1}$,Delsye \\ Teo Ching Lee ${ }^{1}$, Alsidqi Hassan ${ }^{1}$, Siti Kudnie Sahari ${ }^{2}$, Khairul Anwar Mohamad Said ${ }^{3}$, \\ and Habibur Rahman Sobuz ${ }^{4}$ \\ ${ }^{1}$ Civil Engineering Department, Universiti Malaysia Sarawak, 94300 Kota Samarahan, Sarawak, \\ Malaysia \\ ${ }^{2}$ Electrical and Electronic Engineering Department, Universiti Malaysia Sarawak, 94300 Kota \\ Samarahan, Sarawak, Malaysia \\ ${ }^{3}$ Chemical Engineering and Energy Sustainability Department, Universiti Malaysia Sarawak, 94300 \\ Kota Samarahan, Sarawak \\ ${ }^{4}$ Department of Building Engineering and Construction Management, Khulna University of \\ Engineering and Technology (KUET), Khulna, Bangladesh
}

\begin{abstract}
Cement as an essential element for cement-based products contributed to negative environmental issues due to its high energy consumption and carbon dioxide emission during its production. These issues create the need to find alternative materials as partial cement replacement where studies on the potential of utilizing silica based materials as partial cement replacement come into picture. This review highlights the effectiveness of microstructural characterization techniques that have been used in the studies that focus on characterization of calcium hydroxide $(\mathrm{CH})$ and calcium silicate hydrate $(\mathrm{C}-\mathrm{S}-\mathrm{H})$ formation during hydration process of cement-based product incorporating nano reactive silica based materials as partial cement replacement. Understanding the effect of these materials as cement replacement in cement based product focusing on the microstructural development will lead to a higher confidence in the use of industrial waste as a new non- conventional material in construction industry that can catalyse rapid and innovative advances in green technology.
\end{abstract}

\section{Introduction}

In facing the new era, issues of sustainability and durability of construction industry are often emphasized on the pursuit of finding materials as partial cement replacement to decrease the high energy consumption and carbon dioxide emission during cement production [1]. The candidates that can be used as cement replacement must have two characteristics: high reactive silica content and very fine particle size. Any material that has these characteristics can produce pozzolanic reaction that can improve cement based

\footnotetext{
*Corresponding author: msnorsuzailina@unimas.my
} 
product qualities. The scope of this review is on two materials namely spent fluid cracking catalyst (SFCC and nanosilica (nS). The spent fluid cracking catalyst (SFCC) which is produced from the catalytic cracking in petroleum industry is an inorganic waste material [2-3] and its contribution in cement-based production can bring environmental and economic benefits, thus reducing the final cost of cement-based products and the environmental impacts related to cement production and can be used as partial cement or sand replacement[4-5]. The material can be classified as non- hazardous material [6]for cement replacement because it was found that low concentration of heavy metal that can leach out of the SFCC which gives higher confidence in its possible use as a construction material.Other researchers [7] stated that nano-materials have received wide attention for use in the constructions sector and the increasing in the performance has been discovered for these materials in terms of smart functions and sustainable characteristics [8]. Many studies have shown that the contribution of nano silica (NS) in cementitious systems especially in construction of cement-based products is by improving the characteristics of the plastic and hardened material[9]. Silica in the nano-particles size has a filler effect by filling up the voids between the cement grains [10]. Referring to the previous study conducted, [11] stated that silica nano-particles are environmental friendly material and has no impact on health issues. It can help to create something new and sustainable to reduce the use of cement and reduce the cost of final construction works.

In the construction industry, cement replacement with pozzolanic materials, produce cement-based products that help in the positive use of waste materials, saving the environment, reduce carbon dioxide emissions and improve their performance [12-14]. Various methods have been implemented to improve the characteristics of cement-based products in the past [15]. The aim of this paper is to review the possible techniques to characterize the cement hydration products. The possibilities of both materials possessing cementing characteristics are to be studied according to their pozzolanic reaction and pore filling effect. Both materials are classified as pozzolanic where the term pozzolan is defined by previous researchers [16].

As a siliceous or aluminous material, either natural or artificial, which react chemically with calcium hydroxide $(\mathrm{CH})$ or with materials that can release calcium hydroxide in the presence of water to form compounds that possess cementing characteristics.In order to understand the microstructural development caused by pozzolanic reaction from SFCC and NS as partial cement replacement, specialized microstructural characterization techniques were utilized by many researchers. This review will highlight their effectiveness in characterizing calcium hydroxide $(\mathrm{CH})$ and calcium silicate hydrate (C-S-H) formation during hydration process.

\section{Pozzolanic Reactions and Pore Filling Effect of SFCC and NS Materials in Cement Hydration Process}

The pozzolanic reaction is where the reactive siliceous and aluminous phases react with calcium hydroxide $(\mathrm{CH})$ to form new calcium silicate hydrate $(\mathrm{C}-\mathrm{S}-\mathrm{H})$ in the presence of water at room temperature, hence possessing cementitious characteristic. Pore filling effect can be described as the ability of materials to fill in the voids, finally produce dense, compact microstructure and enhance strength of the cement-based products. The hypothesis of cement hydration process, which is influence by partial replacement of both SFCC and NS materials, is described in Fig. 1 and 2: 


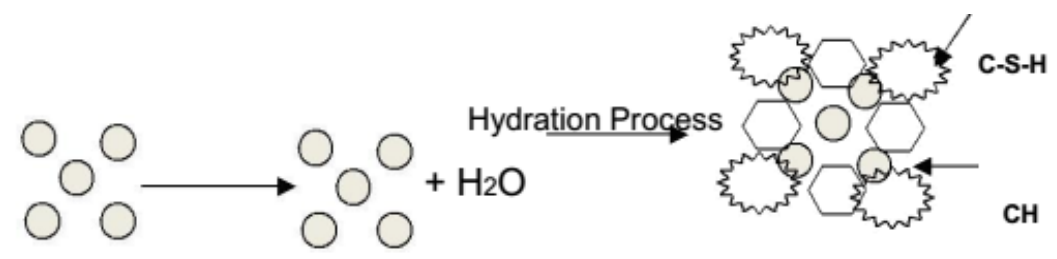

Un-reacted cement Cement reacts with water particles

Formation of $\mathrm{CH}$ and $\mathrm{C}-\mathrm{S}-\mathrm{H}$

Fig. 1. Hydration Process of Ordinary Portland Cement.

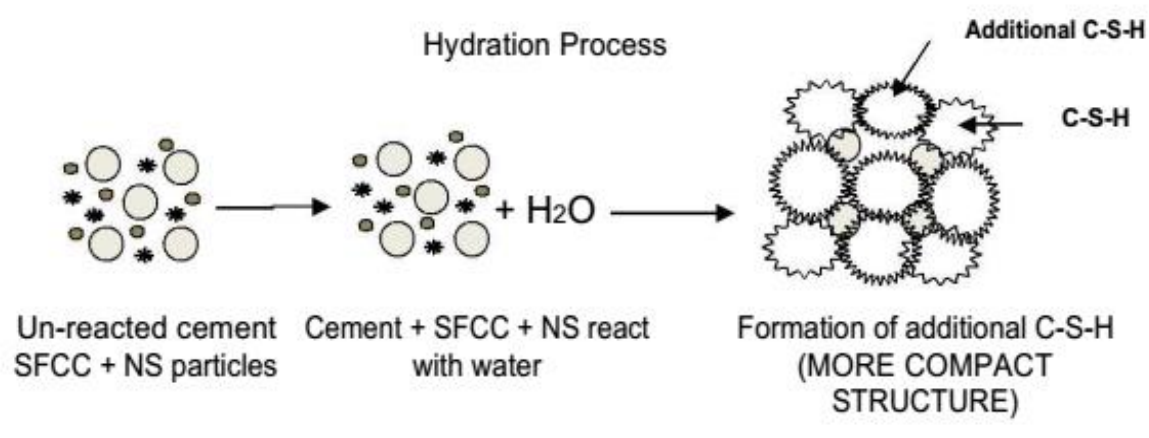

Fig. 2. Hydration Process of Partial Replacement of Cement by SFCC and NS.

In cement hydration process, there are some amounts of $\mathrm{CH}$ remaining in the cement structure. Those remaining $\mathrm{CH}$ can be replaced by consuming them with silica oxide to form additional C-S-H which is the main contribution of cement strength [17]. This silica oxide can be found through the pozzolanic material known as pozzolan where this study used SFCC and NS materials. The chemical reaction occurs in cement hydration process can be described as:

Chemical Reaction in Ordinary Portland Cement (OPC) Hydration Process:

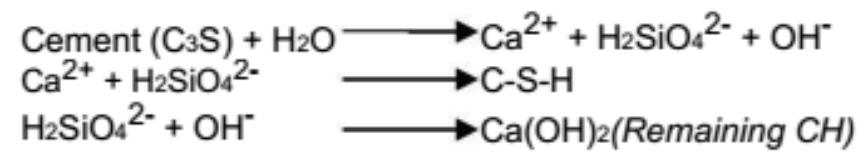

Chemical Reaction in Pozzolan Replacement Cement Hydration Process:

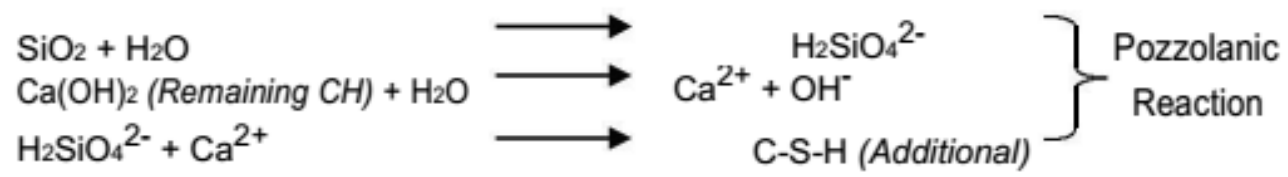


SFCC waste was proven to behave as an excellent pozzolan for early curing age by improving both durability and mechanical behaviour in the cementitious system [18]. According to literature in previous study, SFCC which consists primarily of active silica $\left(\mathrm{SiO}_{2}\right)$ and alumina $\left(\mathrm{Al}_{2} \mathrm{O}_{3}\right)$ [19] shows pozzolanic activity and contributes to the acceleration of the hydration and setting processes [20]. It has been found that, in the compositions with Portland cement, the SFCC waste reacts with calcium hydroxide which is a product of cement hydration as a pozzolanic material [21]. SFCC in a nano-particles size can reduce significantly the porosity [22] of the cement-based products by acting as filler to the voids causing denser microstructures of interfacial transition zone (ITZ) [23].

Pozzolanic reaction of NS with $\mathrm{CH}$, which occurs during the hydration of cement, produces additional $\mathrm{C}-\mathrm{S}-\mathrm{H}$ which is the main constituent for strength and density in the hardened cementitious system [24]. At the same time, $\mathrm{CH}$ which was not contributes to strength development is consumed. Cement-based products with well dispersed NS particles inside it has a dense microstructure even if the NS particles are added in small quantity, but if NS particles are not dispersed properly, it may results in voids and weak zones formation [25]. NS particles act as nucleation sites to accelerate the hydration [26]. Due to high surface area and spherical shape, NS can enhance performance of cementbased material due to pozzolanic reaction of silica with calcium hydroxide, $\mathrm{CH}$ to form additional calcium silicate hydrate, C-S-H which represent the strength of cement-based product [27].As the most widely investigated of nano material in cement and concrete research, NS was found to be effective in enhancing the hydration process [28], the mechanical properties[29], and the durability [30] of cement-based material to a great extent.

\section{Characterization Techniques Used to Confirm Pozzolanic Reaction of SFCC and NS Materials as Partial Cement Replacement.}

\subsection{Scanning Electron Microscopy (SEM)}

SEM is used to study the morphology characteristic in order to confirm the presence of C$\mathrm{S}-\mathrm{H}$ products from the cement hydration process in the form of image analysis. In this study approach, the formation of the additional C-S-H occurs from the pozzolanic reaction is to be confirmed by the image obtained from certain phases of curing ages. The results of those reactions can be seen through the compactness of microstructure image as influence from pore filling effect of the material used. The study on SFCC by previous study [23] indicated that the microstructure of cement-based products appeared quite dense and compact with great modification or improving for interfacial transition zone (ITZ) between cement paste and aggregate. This proved that the pozzolanic reaction occurred in the cement-based product samples where amorphous silica from SFCC reacted with $\mathrm{CH}$ from cement hydration was able to produce additional C-S-H which the composition of those additional C-S-H found to be similar to those obtained in ordinary portland cement hydration. The SEM image indicated that SFCC can enhance the hydration products and improve the microstructure. SEM results reported in other previous study [31] shows that the microstructure of cement-based product partially replaced with NS was denser than cement-based product without the NS replacement because of the pozzolanic reaction by consumption of $\mathrm{CH}$, and formation of additional C-S-H which fill the pores system and causing densification effect which improved the microstructure of cement system. A more 
compact microstructure image caused by pozzolanic reaction in cement-based products with replacement of nano silica was reported in the study done by another researcher [8].

\subsection{Fourier Transformation Infrared Spectroscopy (FTIR)}

FTIR is used to identify the functional group of the hydration products. The $\mathrm{CH}$ and $\mathrm{C}-\mathrm{S}-\mathrm{H}$ amount due to pozzolanic reaction in cement-based products can be measured using this technique. The amount of the chemical compound presence in the cement hydration process might affect the filling ability of those hydration products to fulfil the capillary pores in cement system. The FTIR analysis for SFCC studied in previous [32] indicated the formation of hydrated calcium silicate of the $\mathrm{C}-\mathrm{S}-\mathrm{H}$ gel type as caused by nature alkaline activation of SFCC as the main reaction product. This result showed that the pozzolanic reaction has occurred in the cement- based sample and gave pore filling effect to the cement microstructure as more $\mathrm{C}-\mathrm{S}$ - $\mathrm{H}$ gel produced in the reaction during cement hydration process. The FTIR test result of functional group identification shown in Figure 3[33], a study of characteristics of blended cements containing NS, indicated that NS particles promoted the pozzolanic reaction by transforming $\mathrm{CH}$ into $\mathrm{C}-\mathrm{S}-\mathrm{H}$ gel. The existence of $\mathrm{C}-\mathrm{S}-\mathrm{H}$ was expected to be in the cement system reaction where the FTIR spectra of hydrated cement paste curing up to 90 days showed the band that appeared in the range of 950-980 cm-1 which is assigned to the tobermorite like phase, C-S-H. Meanwhile, in [34] studies using FTIR to characterize $\mathrm{CH}$ and $\mathrm{C}-\mathrm{S}-\mathrm{H}$ formation in the nanopozzolan modified cement using small percentage of NS gave the strongest C-S-H peaks at $970 \mathrm{~cm}-1$ which confirm the pozzolanic reaction in the samples.

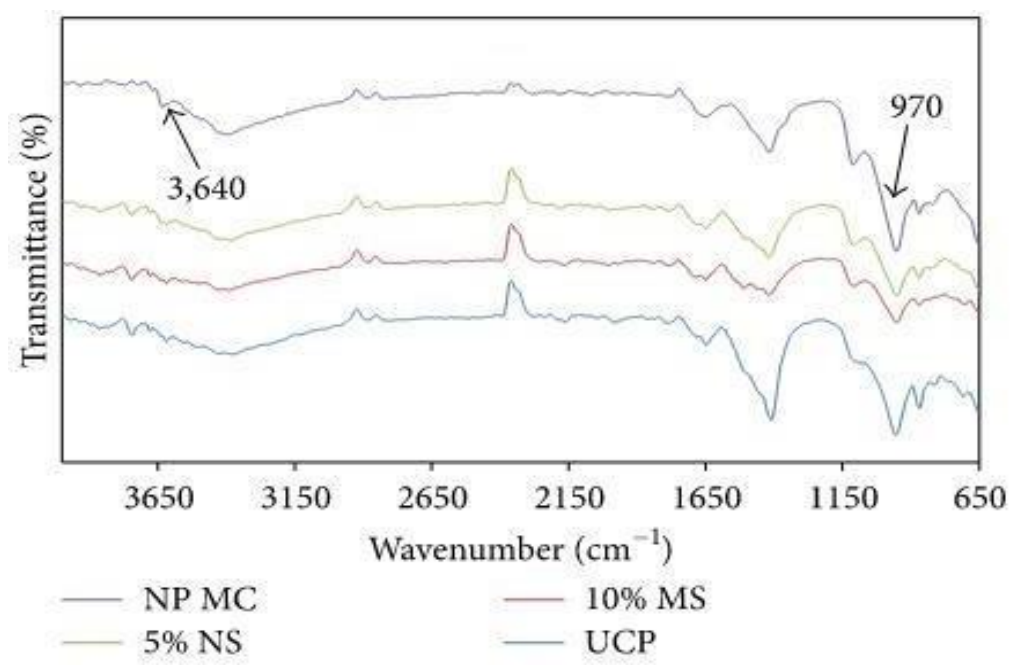

Fig. 3. FTIR spectra for NPMC, 5\% NS, 10\% MS, and UCP on day 28 [33].

\subsection{X-Ray Diffraction (XRD)}

XRD phase analysis is used to characterize and identify the hydration products. Pozzolanic reaction of those materials can be examined in a crystalline structure presenting those $\mathrm{CH}$ and C-S-H formation. The formation of additional C-S-H will influence cement strength and produce denser microstructure of cement-based products. The previous research study[20]using XRD indicated the presence of hydrated calcium silicate, C-S-H at a broad 
diffuse halo $2 \theta$ angle of about $26^{\circ}$ and non-hydrated calcium silicate, CS and portlandite, $\mathrm{CH}$ and silica phases. The presence of those active silica which participated in cement hydration process will enhance pozzolanic reaction, thus chemically convert the remaining $\mathrm{CH}$ during cement hydration into $\mathrm{C}-\mathrm{S}-\mathrm{H}$ which is the strength responsible phase. Author [35] observed in their study an increasing of $\mathrm{CH}$ amount due to the increasing of the C-S-H formation in the 3 days of curing period. The amount of crystalline $\mathrm{CH}$ seems to be decrease in the 28 days of curing period. This was indicated by the shorter length of $\mathrm{CH}$ peaks observed in the longer period of curing. This again showed the pozzolanic reaction of NS with $\mathrm{CH}$ to form additional C-S-H has occurred. Previous researchers [36], also cited that NS was beneficial to promote the pozzolanic reaction as early as the hydration process in cement-based product. It slightly changed the amount of hydration products in 28 days of curing period where the content of the $\mathrm{CH}$ was consumed.

\section{Conclusions}

This paper discusses the possibilities of cement replaced by SFCC and NS materials and their pozzolanic reaction in cement hydration process through characterization techniques analysis in order to investigate the ability of both waste and nano material works together for partial cement replacement. Those catalysis hydration products (additional C-S-H) from the pozzolanic reaction during cement hydration process consider havingpositive influence to improve the characteristics of cement system. The hydration mechanism of cementbased products is still not completely understood. Slow reaction rate of pozzolanic material have left a significant amount of calcium hydroxide $(\mathrm{CH})$ remaining in the cement-matrix during hydration process making the evolution of the pozzolanic reaction should be observed in the long term.

The authors wish to acknowledge Ministry of Higher Education and University Malaysia Sarawak for supporting this work under FRGS/TK04(02)/1138/2014(05)

\section{References}

1. M. S. Norsuzailina, I. Yakub, H. Jau, Applied Mechanics and Materials 695, 643-646 (2014)

2. Y. Huang, X. Chen, Y. Deng, D. Zhou, L. Wang, Chemical Engineering Journal 269, 434-443 (2015)

3. S. V. Payá, Jordi, Jose M. Monzo, Maria V. Borrachero, Ad Cem Res 25, 1-7 (2013)

4. B. Pacewska, M. Nowacka, I. Wilińska, W. Kubissa, V. Antonovich, J Therm Anal Calorim 105(1), 129-140 (2011)

5. K. Alshamsi, M. Baawain, K. Aljabri, R. Taha, Z. Al-kamyani, Procd Soc Behv 53, 326-334 (2012)

6. E. D. Rodríguez, S. A. Bernal, J. L. Provis, J. D. Gehman, J. M. Monzó, J.Payá, M. V. Borrachero, Fuel 109, 493-502 (2013)

7. S. A. E. Mohamed, A. E. Ragab, Int J Eng Res Technol 3(7), 339-358 (2014)

8. H. Biricik and N. Sarier, Mater Res 17(3), 570-582 (2014)

9. P. Hou, S. Kawashima, D. Kong, D. J. Corr, J. Qian, S. P. Shah, Composites Part B: Engineering 45(1), 440- 448 (2013)

10. A.Lazaro Garcia, G. Quercia, H. J. H. Brouwers, J. W. Geus, World Journal of Nano Science and Engineering 3, 41-51 (2013)

11. E. Horszczaruk, E. Mijowska, K. Cendrowski, S. Mijowska, P. Sikora, Construction and Building Materials 66, 418-421 (2014) 
12. H. Gurdián, E. García-Alcocel, F. Baeza-Brotons, P. Garcés, E. Zornoza, Materials 7(4), 3176-3197 (2014)

13. C. Costa, M. S. Ribeiro, N. Brito, Materials Sciences and Applications 5, 905-914 (2014)

14. T. Castellanos, T. Agredo, M. De Gutiérrez, Ingeniería E, Investigacion 33(1), 18-22 (2013)

15. S. Velázquez, J. Monzó, M. Borrachero, J. Payá, Materials 7(4), 2561-2576 (2014)

16. M. S. Amin, S. M. A. El-Gamal, S. A. Abo-El-Enein, F. I. El-Hosiny, M. Ramadan, HBRC Journal, 1687-4048 (2014)

17. V. K. Vadivel Rajendiran, Stalin, Advanced Nanomaterials and Emerging Technologies, 706-712 (2013)

18. L. Soriano, J. Monzó, M. Bonilla, M. M. Tashima, J. Payá, M. V.Borrachero, Cement and Concrete Comp 42, 41-48 (2013)

19. R. Taha, Z. Al-kamyani, K. Al-jabri, M. Baawain, K. Al-shamsi, J Hazard Mater 229230, 122-127 (2012)

20. Y. Morozov, a. S. Castela, a. P. S. Dias, M. F. Montemor, Cement Concrete Res 47, 17 (2013)

21. M. Aleknevic, V. Antonovic, I. Pundien, J Therm Anal Calorim 109, 537-544 (2012)

22. B. Pacewska, M. Nowacka, M. Aleknevičius, V. Antonovič, Procedia Engineering 57, 844- 850 (2013)

23. K. Al-Jabri, H. Shoukry, Construction and Building Materials 73, 636-644 (2014)

24. U. S., S. A. L. P. Singh, S. K. Agarwal, S. K. Bhattacharyya, Nanomater. nanotechnol 1(1), 44- 51 (2011)

25. K. S. S., Maheswaran, Bhuvaneshwari B, Palani G.S, Nagesh R Iyer, Research Journal of Recent Sciences 2, 17-24 (2013)

26. G. L., D. Stephan, J Mater Sci 47, 1011-1017 (2012)

27. N. M. Sutan, I. Yakub, S. Hamdan, Concrete Research Letters 5, 760-767 (2014)

28. M. Stefanidou, I. Papayianni, Composites Part B: Engineering 43(6), 2706- 2710 (2012)

29. S. R., R. F. Sharma Parveen, Journal of Nanomaterials 1-19 (2013)

30. A.B., P. Hosseini, Concrete Research Letters 2(1), 167-180 (2011)

31. S. K. Sayed Abd El-Baky, Sameh Yehia, Nanocon 2013, 5 (2013)

32. C. Kae-Long Lin, Chao-Lung Hwang, Je-Lueng Shie, AIChE - Environmental Progress \& Sustainable Energy Journal, 1-7 (2013)

33. M. Heikal, S. Abd El Aleem, W. M. Morsi, HBRC Journal 9(3), 243-255 (2013)

34. N. M. Sutan, I. Yakub, M. S. Jaafar, K. A. Matori, S. K. Sahari, Journal of Nanomaterials, 1-7 (2015)

35. N.M. Sutan, S. Hamdan, H.R. Sobuz, V.Laja, M.S. Islam, Concrete Research Letters 2(4), 326-33 (2012) 